12

\title{
Экспериментальное исследование электрической прочности акриловой ленты VHB при квазистатическом и импульсном напряжениях
}

\author{
(C) И.В. Смирнов, ${ }^{1}$ R. Springhetti, ${ }^{2}$ B.A. Морозов, ${ }^{1}$ A.A. Лукин ${ }^{1}$ \\ ${ }^{1}$ Санкт-Петербургский государственный университет, \\ 199034 Санкт-Петербург, Россия \\ ${ }^{2}$ Department of Civil, Environmental and Mechanical Engineering, University of Trento, via Mesiano 77, \\ I-38123 Trento, Italy \\ e-mail: i.v.smirnov@spbu.ru
}

(Поступило в Редакцию 24 января 2017 г.)

Исследовано влияние скорости изменения электрического напряжения между электродами на электрическую прочность VHB4905, довольно распространенной акриловой клейкой ленты производства 3М с интересными диэлектрическими свойствами. Получено, что при квазистатическом росте напряжения электрическая прочность ленты VHB4905 может возрастать от 35 до $70 \mathrm{kV} / \mathrm{mm}$, в зависимости от одноосной деформации в диапазоне 0-500\%. При импульсном напряжении электрическая прочность диэлектрика зависит от интенсивности роста напряжения на стадии нарастания импульса. При этом установлено, что для заданной длительности стадии нарастания импульса $(\sim 20 \mathrm{~ns})$ есть пороговая электрическая прочность (минимальное пробивное напряжение), превышающая значение квазистатической электрической прочности в 3.7 paзa.

DOI: 10.21883/JTF.2018.01.45500.2177

Диэлектрические эластомеры (ДЭ) представляют собой класс электроактивных полимеров, характеризующийся электромеханической связью и объединением с другими интересными общими характеристиками, такими как легкий вес, быстрая реакция, высокая эффективность, способность поддерживать большие обратимые деформации, а также дешевизна, что открывает большое разнообразие приложений, начиная от электрических генераторов до электромеханических преобразователей [1-3]. Рабочие характеристики устройств на основе диэлектрических эластомеров зависят от небольших значений диэлектрической проницаемости ДЭ, влекущей к плохой электромеханической связи: для их активации необходимы высокие электрические поля, что может приводить к электрическому пробою диэлектрика.

ДЭ характеризуются высокой деформируемостью, фактически представляющей собой ключевую особенность с точки зрения их применения. Поэтому, поскольку электрическое поле в материале зависит от его текущей конфигурации, это имеет принципиальное значение для определения предельной деформации, совместимой с данным электрическим полем, и наоборот. В то же время можно считать общепризнанным [4], что величина электрической прочности в случае кратковременных и высокоинтенсивных электрических воздействий значительно отличается от статического случая, а также зависит от материала электродов, их геометрии, размера и конфигурации межэлектродного промежутка $[5,6]$, контакта между полимерным образом и электродами. Таким образом, зависимость между электрической прочностью и степенью деформации эластомера оказывается под влиянием совокупности факторов.
Исследованиям импульсной электрической прочности диэлектрических эластомеров еще не уделялось должного внимания. Тем не менее необходимо понимать поведение данных материалов при кратковременных электрических воздействиях для их применения в динамических и циклических электромеханических системах. В настоящей работе представлены результаты экспериментального анализа, сфокусированного на влиянии скорости роста электрического напряжения на электрическую прочность акриловой ленты VHB. Испытания проводились в двух режимах: квазистатическом и импульсном.

Нужно заметить, что ввиду технологической ограниченности установок, связанной с подачей высокого напряжения на электроды, реализация широкого диапазона скоростных режимов генерации напряжения в заданных временны́х и амплитудных характеристиках возможна только на различных установках. Однако сравнение результатов, полученных с помощью различных способов, должно проводиться для одних и тех же электродов и условий контакта между электродами и материалом.

На рис. 1 представлены схемы двух применяемых установок. Испытания для измерения электрической прочности при медленном росте напряжения проводились на установке с батареей конденсаторов емкостью $0.5 \mu \mathrm{F}$. Заряд конденсаторов увеличивался пошагово с интервалом $0.25 \mathrm{kV}$ до момента пробоя.

Испытания при импульсном напряжении осуществлялись на установке на базе генератора коротких высоковольтных импульсов ГКВИ-300 со следующими параметрами: энергия $U \approx 60 \mathrm{~J}$, амплитуда напряжения $V=$ $=100-300 \mathrm{kV}$, длительность импульса $T=100-300 \mathrm{~ns}$. 

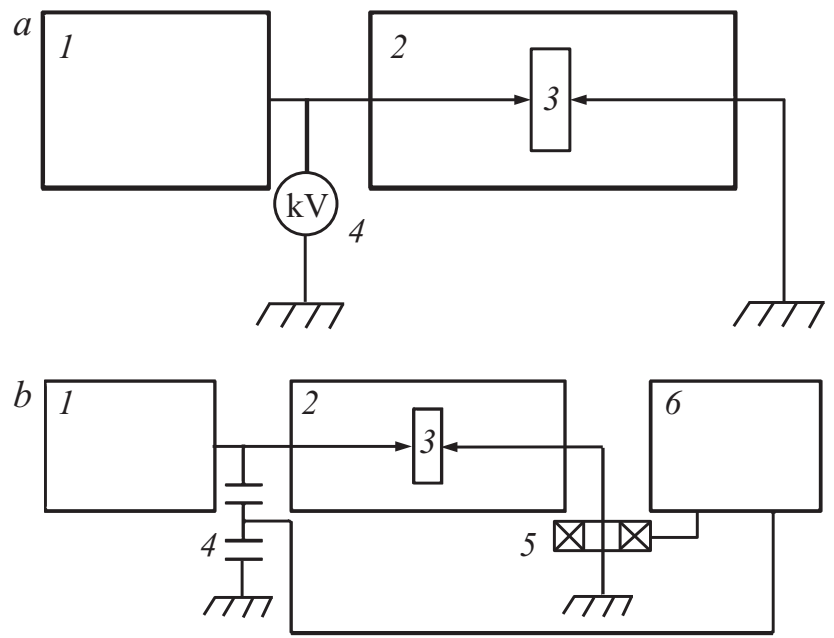

Pис. 1. Схема установок для исследования электрического пробоя в различных режимах. $a-$ квазистатический режим: 1 - батарея конденсаторов, 2 - экспериментальная камера с электродами, 3 - образец, 4 - киловольтметр; $b-$ импульсный режим: 1 - генератор коротких высоковольтных импульсов, 2 - экспериментальная камера с электродами, 3 образец, 4 - измеритель напряжения, 5 - измеритель тока, 6 - осциллограф.

В каждом эксперименте с помощью емкостного делителя напряжений (рис. $1, b, 4)$ контролировался импульс напряжения, прикладываемый между электродами, а с помощью пояса Роговского (рис. 1,b, 5) замерялся ток, проходящий через образец. По разнице во времени между началом осциллограмм напряжения и тока определялся момент электрического пробоя, и в этот момент фиксировалась величина напряжения, при которой произошел пробой. В экспериментах варьировалась амплитуда импульса, а длительность импульса и время нарастания импульса были постоянны $(\sim 100$ и $\sim 20 \mathrm{~ns}$ соответственно).

Испытания проводились на акриловой ленте $3 \mathrm{M}^{\mathrm{TM}}$ VHB4905 толщиной $0.5 \mathrm{~mm}$. Благодаря высокой диэлектрической проницаемости (до $\varepsilon_{r}=6$ ) в классе ДЭ и возможности обратимой деформации более $100 \%$ данный материал широко применяется для устройств на основе ДЭ, и, как следствие, он служит модельным материалом при исследовании поведения диэлектрических эластомеров в условиях высоких напряжений и больших деформаций [5-7].

Лента VHB размещалась между плоскими торцами стальных цилиндрических электродов ( $\varnothing 5 \mathrm{~mm})$. Контакт электродов с лентой обеспечивался адгезионным клеевым слоем на поверхности ленты. В случае импульсных испытаний электроды с лентой размещались в ванне с дистиллированной водой для предотвращения электрического пробоя между электродами по поверхности ленты.

Для определения влияния деформации на величину пробивного напряжения была проведена серия дополнительных экспериментов по квазистатическому про- бою при одноосной деформации диэлектрической ленты. В экспериментах замерялись продольное удлинение и поперечное сужение ленты в области контакта электродов с лентой в результате одноосного растяжения. Продольное удлинение определялось как $\varepsilon=\Delta l / l_{0} 100 \%$, где $\Delta l$ соответствует удлинению участка с начальной длиной $l_{0}$.

На рис. 2 представлены результаты квазистатических испытаний. При увеличении деформации происходит уменьшение пробивного напряжения, при этом электрическая прочность возрастает. Эти данные находятся в полном согласии с предыдущими экспериментальными исследованиями зависимости электрической прочности диэлектриков от текущей толщины $[8,9]$; в частности, в работе [9], где электрическая прочность VHB4910 (тот же материал, но толщиной $1 \mathrm{~mm}$ ) была определена для двуосного растяжения. Как видно на рис. 2, $b$, который повторяет участок на рис. 6 в [9], диэлектрическая прочность меняется от 35 до $70 \mathrm{kV} / \mathrm{mm}$ для обратных значений толщины после деформации между 1 и $10 \mathrm{~mm}^{-1}$ соответственно.

На рис. 3 представлены результаты импульсных испытаний. Испытания проводились только для исходной
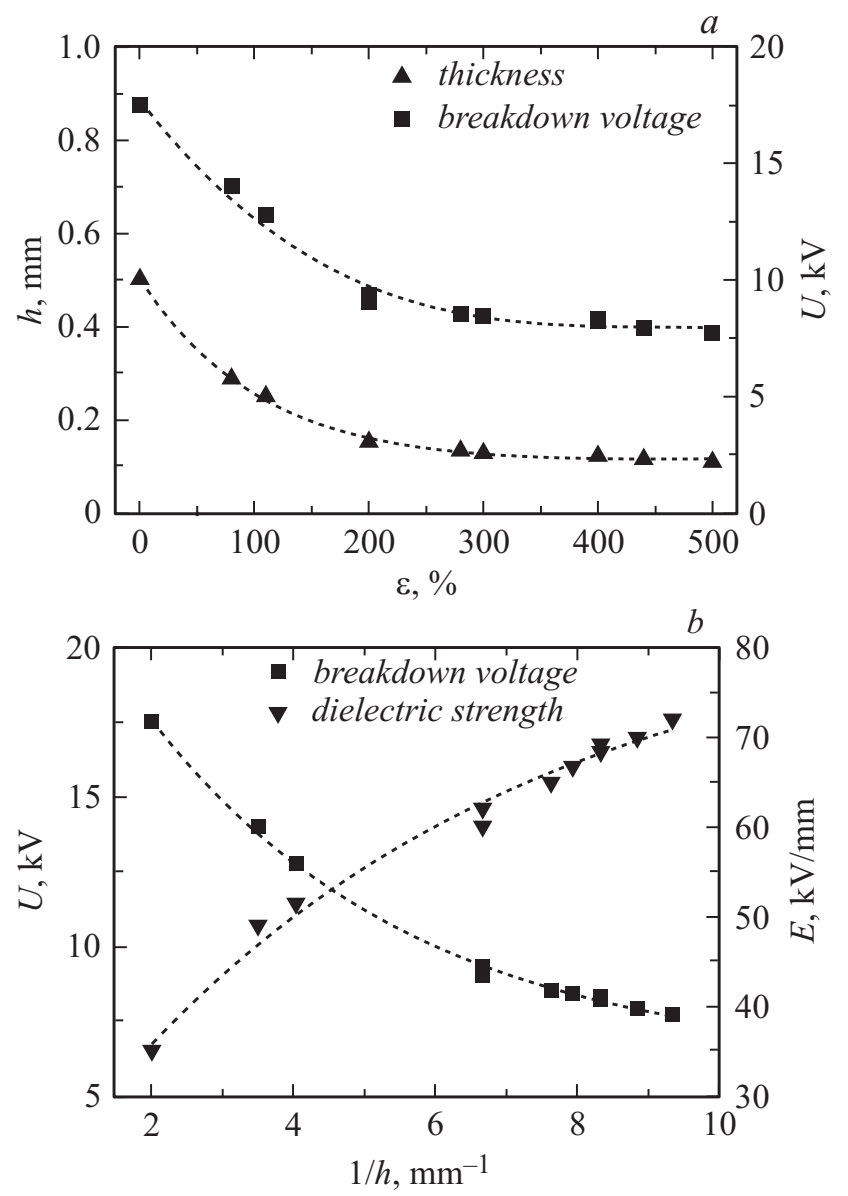

Рис. 2. Пробивное напряжение $(a)$ и электрическая прочность $(b)$ акриловой ленты VHB4905 в зависимости от степени одноосной деформации. Штрих - полиномиальное приближение $(a)$ и экспоненциальное приближение $(b)$. 

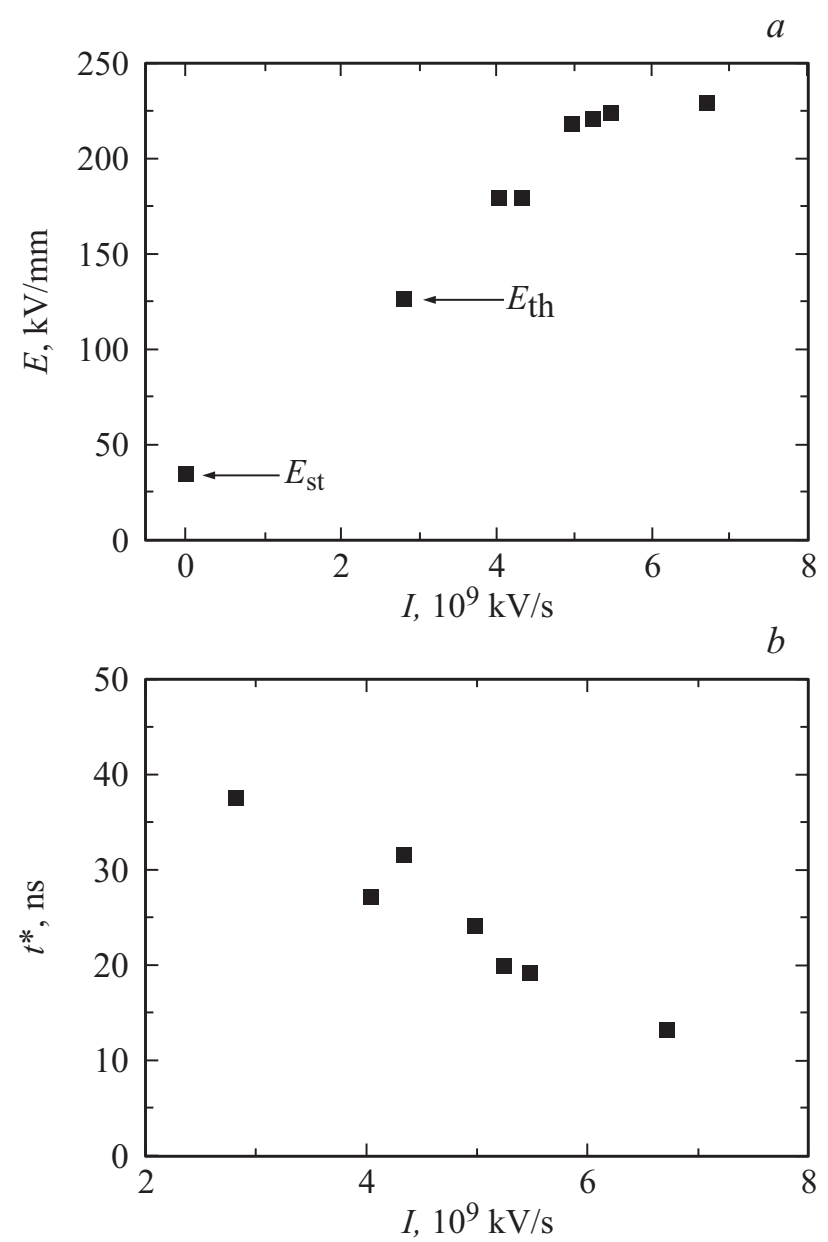

Рис. 3. Электрическая прочность $(a)$ и время до электрического пробоя $(b)$ акриловой ленты VHB4905 в зависимости от скорости нарастания электрического напряжения при импульсных испытаниях.

толщины ленты. Интенсивность импульса определялась как отношение амплитуды импульса к времени нарастания. Из рис. 3 видно, что электрическая прочность растет, а время до электрического пробоя уменьшается при увеличении скорости роста напряжения в импульсе. Важно отметить, что была получена пороговая электрическая прочность $E_{t h}$ для заданной скорости роста напряжений $2.8 \cdot 10^{9} \mathrm{kV} / \mathrm{s}$. Это значит, что снижение амплитуды электрического импульса при той же длительности нарастания напряжения не будет приводить к пробою. Заметим, что пороговая импульсная электрическая прочность $E_{t h}$ (для заданной формы и длительности импульса) превышает квазистатическую электрическую прочность $E_{s t}$ в 3.7 раза.

Из рис. 3 может быть получена хорошо известная вольт-секундная характеристика диэлектриков: зависимость электрической прочности материала от времени воздействия. Согласно $[8,10]$, данная характеристика определяется временем формирования разряда, необходимым для данных условий развития канала пробоя. Отсюда следует, что вольт-секундная характеристика позволяет установить „безопасные“ параметры источника высоковольтных импульсов. Таким образом, полученные экспериментальные данные о динамической зависимости электрической прочности диэлектрического эластомера позволяют предположить, что применение более скоростных генераторов высоких напряжений позволит снизить вероятность электрического пробоя материала при деформации материала в динамических электромеханических системах.

Работа выполнена при поддержке гранта фонда Марии Кюри (FP7 IRSES MARIE CURIE Project „TAMER“ No. 610547).

\section{Список литературы}

[1] Pelrine R., Kornbluh R., Pei Q., Joseph J. // Science. 2000. Vol. 287. P. 836-839.

[2] Suo Z. // Acta Mechan. Sol. Sinica. 2010. Vol. 23. N 6. P. 449 578.

[3] McKay T.G., O'Brien B.M., Calius E.P., Anderson I.A. // Appl. Phys. Lett. 2011. Vol. 98. P. 142903.

[4] Mesyats G.A. // Tech. Phys. Lett. 2005. Vol. 31. N 12. P. $1061-$ 1064.

[5] Qiang J., Chen H., Li B. // Smart Mater. Struct. 2012. Vol. 21. P. 025006.

[6] Jean-Mistral C., Sylvestre A., Basrour S., Chaillout J.-J. // Smart Mater. Struct. 2010. Vol. 19. P. 075019.

[7] Jiang L., Betts A., Kennedy D., Jerrams S. // Mater. Sci. Engineer. C. 2015. Vol. 49. P. 754-760.

[8] Vorob'ev G.A., Nesmelov N.S. // Soviet Phys. J. 1979. Vol. 22. N 1. P. 70-80.

[9] Kofod G., Kornbluh R., Pelrine R., Sommer-Larsen P. // J. Intell. Mater. Syst. Struct. 2003. Vol. 14. P. 787-793.

[10] Воробьев А.А., Воробьев Г.А., Завадовская Е.К. и др. Импульсный пробой и разрушение диэлектриков и горных пород. Томск: Изд-во Томского ун-та, 1971. 